\title{
ACTUALIZACIONES
}

\section{La respuesta de shock térmico y el dimorfismo en Leishmania}

\author{
Diana M. Isaza Guzmán
}

\begin{abstract}
Resumen
Los protozoos del género Leishmania son parásitos intracelulares con dos formas distintas de desarrollo, promastigote y amastigote, las cuales se presentan durante su ciclo de vida entre el hospedero invertebrado y el hospedero mamífero vertebrado, respectivamente. Durante este ciclo el parásito experimenta grandes variaciones de temperatura y el éxito de la transformación entre una y otra forma es crucial para su supervivencia y reproducción.
\end{abstract}

La respuesta de los organismos a la temperatura o respuesta de shock térmico ha sido bien estudiada en Leishmania, obteniendo promastigotes a $26^{\circ} \mathrm{C}$ y amastigotes a $35^{\circ} \mathrm{C}$ y demostrando su reconversión al aumentar o disminuir la temperatura. Estos cambios en la morfología están acompañados de cambios bioquímicos y moleculares, con diferencias en las actividades enzimáticas y en la síntesis proteica, la cual incrementa la producción de proteínas de shock térmico, específicamente HSP70 y HSP83, las cuales permanecen constitutivamente expresadas en los amastigotes de Leishmania como una forma de adaptación al medio ambiente del hospedero vertebrado.

A nivel molecular se ha demostrado que la mayoría de los genes estructurales de estas proteínas están dispuestos en repeticiones en serie los cuales se transcriben en RNA policistrónicos y son posteriormente procesados por poliadenilación y transsplicing; sinembargo no ha sido posible identificar ningún promotor de la transcripción en estos parásitos. Además, los estudios de regulación transcripcional han demostrado que la regulación de la expresión del gen de shock térmico en Leishmania ocurre por procesos postranscripcionales, hecho que ha marcado una diferencia fundamental entre Leishmania y los demás eucariotes no protozoos.

\section{Summary}

Protozoa of the Leishmania genus are intracellular parasites having two different stages, promastigote and amastigote, which are present during their life cycle in the invertebrate host and the mammal host respectively. During its life cycle, the parasite suffers dramatic temperature changes and the transformation success between one and the other form is crucial for its survival and reproduction.

The response of the organisms to temperature or heat shock response has been well studied in Leishmania, promastigotes having been obtained at $26^{\circ} \mathrm{C}$ and amastigotes at $35^{\circ} \mathrm{C}$ respectively, and their reconversion when the temperature is increased or low-

Bacterióloga, Instituto Colombiano de Medicina Tropical y Estudiante IV nivel de Magister en Ciencias Básicas Biomédicas, Universidad de Antioquia. Medellín, Colombia. 
ered has been demonstrated. These changes in parasite morphology are accomplished by biochemical and molecular variations with differences in enzyme activity and protein synthesis. These processses increase the production of heat shock proteins, specifically HSP70 and HSP83, which continue to be expressed as part of the Leishmania amastigotes as a way of adaptation to vertebrate host environment.

At a molecular level, it has been demonstrated that almost all heat shock proteins' structural genes are arranged in tandem repetition, being transcribed in polycystronic RNA and finally processed by poly-adenylation and trans-splicing. Nevertheless, it has not been possible to identify any transcription promoter in these parasites. Furthermore, studies of transcriptional regulation have demonstrated that the regulation of heat shock proteins' gene expression in Leishmania occurs by post-transcriptional processes. This demonstration has marked a fundamental difference between Leishmania and the other non-protozoal eucariotes.

\section{La respuesta de shock térmico y el dimorfi- mo en leishmania}

Los protozoos del género Leishmania son parásitos intracelulares obligados que experimentan grandes variaciones de temperatura debido a su ciclo de vida digenético entre el hospedero invertebrado y el hospedero mamífero vertebrado (1). Así, durante su desarrollo, se ven enfrentados a temperaturas de $22-28^{\circ} \mathrm{C}$ en el vector, y después de ser transmitidos al hospedero mamífero son expuestos a temperaturas más elevadas $\left(31-35^{\circ} \mathrm{C}\right)$ en las lesiones de piel y hasta $37^{\circ} \mathrm{C}$ en las formas viscerales de la enfermedad (2).

En este ciclo, los parásitos presentan dos formas distintas de desarrollo: el promastigote, el cual es una forma flagelada elongada que se encuentra libre en el tracto digestivo de los insectos flebotomíneos, y puede cultivarse a temperatura ambiente en medios libres de células, mientras que en los hospederos mamiferos vertebrados se encuentra la forma de amastigote, no flagelar, ovoide y más pequeña, el cual es un parásito intracelular obligado de los macrófagos en el fagolisosoma. Estos organismos intracelulares han sido cultivados "in vitro" a la temperatura del cuerpo en líneas de macrófagos (3-4). Los promatigotes son inoculados por el vector en el hospedero mamífero, donde ellos rápidamente penetran células susceptibles y sufren una transformación a la forma de amastigote. El éxito de esta transformación es crucial para la supervivencia y la reproducción asexual (3-4). De esta manera las fluctuaciones de temperatura hacen parte de la rutina de este parásito durante el ciclo de vida (5). Sin embargo, además de la temperatura, los promastigotes responden a la acidificación de su entorno cambiando la expresión de un número de genes. De esta manera, la combinación de $\mathrm{pH}$ bajo con alta temperatura induce la transformación del promastigote a amastigote en todas las especies examinadas hasta la fecha (2).

En forma general, muchas células, cuando son expuestas a estímulos nocivos, responden alterando la síntesis proteica. Debido a que la elevación de la temperatura fue el primer estímulo observado que llevaba a esta respuesta, se le llamó Respuesta de Shock Térmico (HSR) y a las proteínas inducidas Proteínas de Shock Térmico (HSP) (6) las cuales varían entre 6 y $110 \mathrm{kDa}$ aproximadamente. La HSR es un mecanismo homeostático general que protege las células y los organismos de los efectos deletéreos de la presión (estrés) ambiental (7), y juega un papel fundamental en la interacción hospederoparásito. El hospedero algunas veces reacciona a la presencia del parásito incrementando su temperatura, bien sea localmente (inflamación) o sistémicamente (fiebre), un efecto históricamente explotado por los antiguos galenos quienes hacían el tratamiento de la sífilis mediante fiebre inducida por malaria 
(8). Esta HSR fue descrita inicialmente por Ritossa en 1962 (8) como parte de un estudio de cromosomas en larvas de Drosophila expuestas a altas temperaturas. Sin embargo, la HSR ocurre desde $4^{\circ} \mathrm{C}$ en los peces antárticos hasta los $88^{\circ} \mathrm{C}$ en la bacteria termofílica Sulfolobus (7).

Algunos investigadores han considerado las Proteínas de Shock Térmico como representantes de un mecanismo primitivo no inmunológico para la discriminación propio/no propio (8). Una amplia variedad de otros factores inducen una respuesta muy similar a nivel celular, tales como el etanol, desacopladores de la fosforilación oxidativa, inhibidores de los componentes del transporte de electrones, hormonas esteroideas, prostaglandinas, infecciones virales, interleuquina- 2 y radicales libres de oxígeno generados como primera línea de defensa antiparasítica (7-8). Algunas HSP son expresadas constitutivamente en los organismos y en ocasiones son el producto celular más abundante. Además, los parásitos que se mueven de un medio ambiente poiquilotérmico a un hospedero, homeotérmico incrementan la síntesis de HSP homólogas a las del hospedero, y su producción es constitutiva durante la permanencia del parásito en el hospedero mamífero (8).

Este tipo de respuesta es universal, pues se ha observado en bacterias, eucariotes inferiores, plantas y humanos (7). Además, no solo es altamente conservada, sino que las HSP de muchos organismos tienen secuencias de aminoácidos similares (8).

La HSR es una reprogramación rápida y transitoria de las actividades celulares que involucra de manera característica la activación transcripcional y/o la activación de los genes de shock térmico con una disminución en la transcripción de otros genes y una traducción selectiva del RNA mensajero (RNAm) de shock térmico produciendo un número restringido de proteínas $(6,8)$. En eucariotes no protozoos, la activación por la temperatura es mediada por un elemento en cis Ilamado Elemento de
Shock Térmico (HSE), localizado a 80-150 nucleótidos "corriente arriba» (upstream) del sitio de iniciación de la transcripción del RNA de todos los genes termoinducibles. Este elemento es una secuencia de nucleótidos altamente conservada llamada Factor de Shock Térmico (HSF) que es específica para proteínas de shock térmico de unión al DNA (7). Esta interacción da como resultado la activación de la transcripción del gen de Shock Térmico (HS)(2). HSF específicos han sido identificados en Drosophila, en células HeLa y en Saccharomyces cerevisiae (7). Sin embargo, poco se conoce acerca de la localización o características de los promotores del gen en Leishmania y otros Tripanosomatídeos (2).

La síntesis de HSPs se correlaciona con la adquisición de termotolerancia a diferentes temperaturas letales protegiendo los organismos no solamente de la letalidad sino también de los defectos en el desarrollo inducidos por calor (7). Algunas HSP son llamadas Chaperonas ya que ellas acompañan el plegamiento de la proteína apropiada y la translocación en células no sometidas a estrés (6). Las HSP son clasificadas operacionalmente con base en su peso molecular. La mejor estudiada ha sido la HSP70, la cual se ha descrito como proteína chaperona; además, se ha demostrado que afecta el plegamiento de las proteínas en una forma que facilita su transferencia a través de membranas celulares. Las HSP que varían de $80-110 \mathrm{kDa}$ (HSP-83) se ha demostrado que afectan el ensamblaje de los elementos del citoesqueleto (8). Ambas proteínas son las más abundantes y altamente conservadas a través de la evolución (9).

Por otro lado, las Proteínas de Shock Térmico se han considerado de gran importancia en la relación hospedero-parásito porque:

1. Según el papel protector propuesto, tanto el hospedero como el parásito podrían usar las HSP como protección contra los aspectos nocivos de la relación (6).

2. Participan en la adaptación del parásito al hospedero mamífero tanto en los fenómenos de diferenciación como de infectividad del parásito (10). 
3. Las HSP producidas por un parásito podrían ser reconocidas como antígeno por el hospedero en sus secuencias no conservadas, activando de esta manera la respuesta inmune. La homología entre las HSP del hospedero y el parásito podría llevar a una respuesta inmune insuficiente o a una respuesta autoinmune (6).

\section{Leishmania y HSR.}

Las primeras descripciones de los efectos de la temperatura sobre los hemoflagelados fueron hechas por Trager (1953), De Castro y Pinto (1960), Neva et al (1961) y Trejos et al (1963), quienes postularon que la temperatura ambiental era un factor crucial en determinar la morfología del parásito. Específicamente, Trager reportó la obtención de formas aflagelares de Leishmania donovani a $37^{\circ} \mathrm{C}$, mientras cultivos similares a $25^{\circ} \mathrm{C}$ produjeron leptomonas flageladas (11).

Los experimentos realizados con Leishmania enriettii por Greenblat y Glaser (11), sometiendo este parásito a diferentes temperaturas por encima de $30^{\circ} \mathrm{C}$, demostraron importantes cambios desde el punto de vista estructural y metabólico, tales como disminución en la viabilidad, aumento de la capacidad respiratoria, pérdida del flagelo y formación de cuerpos de inclusión (probablemente de origen lipídico), acumulación de fósforo inorgánico, y pérdida de guanosina, uracilo, hipoxantina, ribosa y al menos 13 aminoácidos.

Los trabajos de Hunter et al (3) con Leishmania mexicana demostraron, desde el punto de vista ultraestructural, que las formas de amastigote obtenidas a $34^{\circ} \mathrm{C}$ no eran promastigotes sin flagelo, especialmente por el tamaño de la mitocondria, la cual presentaba dimensiones menores a lo observado en los promastigotes típicos, y encontraron una gran similaridad entre estas formas derivadas de cultivo y los amastigotes intracelulares obtenidos de una línea de macrófagos, como también la reconversión de amastigote a promastigote con la disminución de la temperatura a $26^{\circ} \mathrm{C}$. Una respuesta similar se observó también en $L$. braziliensis panamensis (12). Así, además de las diferencias morfológicas encontradas entre amastigotes y promastigotes, existen cambios bioquímicos y moleculares cualitativos y cuantitativos que incluyen variaciones en las actividades enzimáticas, diferencias en el nivel de proliferación, propiedades antigénicas y el patrón de síntesis proteica (5).

A nivel de la síntesis proteica, se ha comprobado que la exposición a alta temperatura produce desactivación en la síntesis de tubulina y otras proteínas del promastigote, observándose un aumento entre 2 y 4 veces en la síntesis de HSP70 y 83 . Este efecto se vio en todas las fases de la curva de crecimiento de los promastigotes, excepto en los de fase estacionaria (5). Las proteínas de shock térmico HSP-70 y HSP-83 son inducidas antes de los cambios morfológicos y permanecen constitutivamente expresadas en amastigotes de Leishmania. Otras condiciones ambientales tales como el estrés nutricional también contribuyen a la aparición de HSR, ya que el RNAm específico para HSP-83 se aumenta ligeramente en promastigotes de fase logarítmica tardía y de fase estacionaria, probablemente debido a la depleción nutricional. Esto se correlaciona con el incremento de la virulencia que se observa en los promastigotes de fase estacionaria. Se cree que existen condiciones similares en el vector, inme-diatamente antes de alimentarse cuando los promastigotes sufren una deprivación nutricional. La presencia de proteínas de estrés antes de la transmisión del parásito podría preadaptarlo al estrés adicional en el hospedero mamífero (5).

La diferencia en la expresión de HSP y RNAm en promastigotes de fase estacionaria sugiere que la regulación de las HSP podría estar controlada a nivel transcripcional así como postranscripcional posiblemente por una tradución preferencial de los RNAm (5).

Se ha demostrado que la HSP-70 se expresa constitutivamente en los amastigotes, lo cual sugiere que esta proteína es esencial para la adquisición de termotolerancia y supervivencia dentro del hospedero vertebrado, y más pro- 
bablemente involucrada en los procesos que llevan a la diferenciación. El papel de esta proteína en Leishmania es aún desconocido. Los estudios en otros sistemas han demostrado que la HSP-70 está involucrada en la ruptura dependiente de ATP de agregados proteicos hidrofóbicos (9).

La organización del genoma de los kinetoplástidos es única entre los eucariotes (1). La mayoría de los genes estructurales que codifican proteínas están dispuestos en repeticiones en serie ("tandem") que se transcriben en RNA policistrónicos, los cuales son posteriormente procesados por poliadenilación y trans-splicing $(1,13-14)$, en la cual una porción de 39 nucleótidos, llamada secuencia líder de empalme (spliced leader-SL) se une a su extremo $5^{1}$. EI SL es donado a pre-RNAm desde un pequeño transcripto de SL RNA independiente, el cual le confiere al RNAm una estructura en casquete que es requerida para el trans-splicing, iniciación de la traducción y estabilidad del RNAm (13). Las regiones codificantes están interespaciadas por regiones intergénicas (IR), de las cuales la mayoría se transcriben pero no se traducen (14). Los sitios de iniciación de transcripción del RNA se pierden del RNAm durante el proceso de maduración, ya que el trans-splicing suprime los sitios de iniciación y hay muy pocos datos sobre la naturaleza de los elementos promotores transcripcionales $(1,14)$. Unos pocos promotores fueron recientemente caracterizados en Trypanosoma brucei mostrando características de Pol-1; sin embargo, éstos no eran activos en Leishmania y no mostraron homología a ningún promotor de eucariotes superiores. Ningún promotor ha sido localizado o identificado para ninguno de los genes estructurales de Leishmania (1).

Las primeras evidencias moleculares de la HSR en Leishmania fueron presentadas por Van der Ploeg et al (15) en 1985, quienes demostraron en experimentos realizados con L. major, que los niveles de RNAm de los genes relacionados a la HSP-70 y HSP-83 presentaban diferencias cualitativas y cuantitativas entre promastigotes, y amastigotes, siendo mayor la expresión de estas proteínas en la forma de amastigote; además, los patrones de transcripción específica de shock térmico en amastigotes y promastigotes sometidos a alta temperatura, fueron similares, demostrando así a nivel molecular que la diferenciación del parásito resulta por un cambio de temperatura que afecta los genes del shock térmico. Este tipo de respuesta no parecía interferir con la proliferación celular (15).

Aunque las HSP se han estudiado intensamente en protozoos parásitos, la regulación transcripcional en respuesta a HS no había sido posible estudiarla en estos organismos hasta hace poco, cuando los sistemas de transfección llegaron a ser disponibles (1).

Con el fin de explorar los mecanismos regulatorios en Leishmania, se escogió el gen que codifica HSP83, la cual se expresa abundantemente en promastigotes y amastigotes. Este gen está dispuesto en repeticiones en tandem agrupadas sobre un cromosoma de $1 \mathrm{Mb}$. El mapeo de su RNAm demostró que la mayoría de las unidades de repetición genómica $(3.6 \mathrm{~Kb})$ es transcrito. Además del gen que codifica $2.1 \mathrm{~Kb}$, el RNAm incluye $0.3 \mathrm{~Kb}$ de secuencias no transcritas "corriente arriba» (upstream) y una sección de $0.9 \mathrm{~Kb}$ no transcrita "corriente abajo» (downstream), dejando una región intergénica no transcrita de $0.3 \mathrm{~Kb}(2)$. Se ha observado que el nivel más alto de su RNAm se acumula cuando la temperatura es cambiada de $26^{\circ} \mathrm{C}$ a $35^{\circ} \mathrm{C}$ y en el estado de amastigote. Argaman et al (16) caracterizaron la regulación del gen de HSP83 y demostraron que el RNAm se acumulaba a elevadas temperaturas debido principalmente a su incrementada estabilidad a la temperatura de los mamíferos $\left(35^{\circ} \mathrm{C}\right)$, mientras que a $26^{\circ} \mathrm{C}$ era rápidamente degradado. Sinembargo, mientras los transcriptos se acumulaban a $35^{\circ} \mathrm{C}$, no hubo evidencias de activación en la transcripción del gen de HSP83. En la búsqueda de mecanismos de control diferentes a la activación transcripcional, se encontró que las variaciones en los niveles del RNAm de HSP83 se debían principalmente a un mecanismo dependiente de la temperatura para la degradación del RNAm sugiriendo un mecanismo de regulación postranscripcional (16). 
La degradación a $26^{\circ} \mathrm{C}$ del RNAm de HSP83 en Leishmania se correlaciona con la síntesis de proteína activa $(2,16)$. Esto sugiere que el nivel de RNAm de HSP83 pudiera estar controlado por una nucleasa lábil, la cual es activa principalmente a $26^{\circ} \mathrm{C}$. Alternativamente, la degradación pudiera ser dependiente de la traducción y requerir un factor que se asocie con los ribosomas o una estructura estéreoespecífica que ocurre durante la traducción $(2,16)$. Usando un sistema de transfección fue posible demostrar que los elementos de control para la degradación del RNAm de HSP83 dependiente de temperatura estaban incluídos dentro de las secuencias IR (16).

La regulación de HSP83 en Leishmania difiere de lo observado en eucariotes no protozoos. El Shock Térmico lleva a la interacción entre el HSF y el HSE en Drosophila, células HeLa y levaduras. En todos estos organismos no protozoos, el aumento de la temperatura produce la activación transcripciolal de los genes del shock térmico (16). Sinembargo, en Leishmania la exposición a una temperatura de $35^{\circ} \mathrm{C}$ lleva a una respuesta de estrés, pero no se observa activación transcripcional del gene de HSP83. Los estudios preliminares para identificar HSEs dentro de las secuencias IR de genes de shock térmico en tripanosomatídeos mostró elementos del DNA con homologías parciales, pero no se conoció su función. La regulación postranscripcional de HSP70 ha sido observada en células HeLa y en Drosophila. Sin embargo, en estos organismos era complementada por activación transcripcional, lo cual no se observa en Leishmania (16).

La abundancia de HSP83 en Leishmania a bajas temperaturas sugiere que esta proteína es también esencial para la existencia bajo condiciones diferentes al shock térmico, además de su contribución en la adquisición de termotolerancia (16).

En conclusión, la regulación de la expresión del gen de las proteínas de shock térmico en Leishmania ocurre por procesos postranscripcionales enfatizando una diferencia importante entre Leishmania y eucariotes no protozoos.

\section{Referencias}

1. Aly R, Argaman M, Pinelli E, Shapira M. Intergenic sequences from the heat-shock protein 83-encoding gene cluster in Leishmania mexicana amazonensis promote and regulate reporter gene expression in transfected parasites. Gene 1993;127:155-63.

2. Zilberstein $\mathrm{D}$, Shapira $\mathrm{M}$. The role of $\mathrm{pH}$ and temperature in the development of Leishmania parasites. Ann Rev Microbiol 1994; 48:449-70.

3. Hunter KW Jr, Cook CL, Hensen SA. Temperature-induced in vitro transformation of Leishmania mexicana. Acta Trop 1982;39:143-50.

4. Pan AA. Leishmania mexicana: Serial cultivation of intracellular stages in a cell-free medium. Exp Parasitol 1984;58:72-80.

5. Shapira M, McEwen JG, Jaffe CL. Temperature effects on molecular processes which lead to stage differentiation in Leishmania. EMBO J 1988;7:2895-2901.

6. Davis SR, Lushbaugh WB. Characterization of the heat-shock response of Trichomonas vaginalis. Am J Trop Med Hyg 1992;47:70-7.

7. Maresca B, Carratú L. The biology of the Heat Shock Response in Parasites. Parasitol Today 1992;8:260-66.

8. Newport G, Culpepper J, Agabian N. Parasite heatshock proteins. Parasitol Today 1988;4:306-12.

9. Shapira M, McEwen JG, Jaffe CL. In vitro and in vivo differentiation of L. mexicana-Hsp70 gene expression. In: Hart DT editor. Leishmaniasis. Plenum Publishing Corporation, 1989:575-79.

10. Polla BS. Heat shock proteins in host-parasite interactions. En: Ash C, Gallagher RB, editors. Immuno-parasitology Today. Combined Issue 1991: A38-A41.

11. Greenblatt CL, Glaser P. Temperature effect on Leishmania enriettii in vitro. Exp Parasitol 1965;16:36-52.

12. Darling TN, Blum. In vitro reversible transformation of Leishmania braziliensis panamensis between promastigote and ellipsoidal forms. Protozool 1987;34:166-68.

13. Agami R, Aly R, Halman S, Shapira M. Functional ana-lysis of cis-acting DNA elements required for expression of the SL RNA gene in the parasitic protozoan Leishmania amazonensis. Nucl Acids Res 1994;22:1959-65.

14. Aly R, Argaman M, Halman S, Shapira M. A regulatory role for the $5^{\prime}$ and $3^{\prime}$ untranslated regions in differential expression of HSP83 in Leishmania. NuclAcids Res 1994; 22:2922-29.

15. Van der Ploeg LHT, Giannini SH, Cantor CR. Heat Shock Genes: Regulatory role for differentiation in parasitic protozoa. Science 1985;228:1443-46.

16. Argaman M,Aly R, Shapira M. Expression of heat shock protein 83 in Leishmania is regulated post-transcriptionally. Mol Biochem Parasitol 1994;64:95-110. 